\title{
Evaluation of Rice Husk Ash as a Partial Replacement of Cement in Self-Compacting Concrete Using Mix Design
}

\author{
Dipendra Dahal ${ }^{\mathrm{a}}$, Ramesh Banstola ${ }^{\mathrm{b}}$, Nirmal Baral ${ }^{\mathrm{c}}$ and Keshav Basnet ${ }^{\mathrm{d}}$ \\ a,b,c,d Infrastructure Engineering and Management Program, \\ Department of Civil and Geomatics Engineering, \\ Pashchimanchal Campus, \\ Institute of Engineering, \\ Tribhuvan University, \\ Nepal
}

\begin{abstract}
Concrete is basic construction material in the modern construction industry and occupies major cost components. The prime concern is the quality of varying specification in Normal to Special Concrete to meet the design expectation in real Practices. Application of Self-Consolidating Concrete (SCC) in the construction industry provides a potential solution to the limitations facing the use of traditional concrete in densely reinforced structural members. In response to the continual evolution towards an environmentally aware society, there is increasing demand for the application of sustainable building materials and minimizing of waste to landfill. Therefore, it has been identified that the practical application of Rice Husk Ash (RHA) as a Supplementary Cementitious Material (SCM) is capable of reducing both the quantity of Portland cement used in the construction industry, and also the quantity of rice husk contributing as waste to landfill. The aim of this research is to determine the optimum proportion of Rice Husk Ash (RHA) that can be incorporated as a supplementary cementitious material for partial replacement of Portland cement in a self-consolidating concrete. SCC was designed for the use of locally available aggregates and conducted through various trails as per SCC principles whereas RHA was extracted by uncontrolled burning of rice husk. This study was conducted through testing of the Compressive strength of six test samples that differ in amounts of RHA ranging from $0 \%$ to $30 \%$ of total replacement of cement for which Mix design for M20 concrete was calculated using IS mix design method. Outcomes suggest that RHA burnt under the proposed experimental conditions has the potential to be applied as a pozzolanic material which was proved by late gain of compressive strength in significant number shown at 45 days compressive strength.
\end{abstract}

Author Keywords: Compaction; Compressive strength; Self-Consolidating Concrete; Supplementary Cementitious Material.

\section{INTRODUCTION}

Green Concrete stands one of the research field to disseminate the ideas how normal concrete being eco-friendly, energy efficient and reduces greenhouse gaseous by partial replacing the concrete ingredient at various proportions. SCC is popular as the modern concrete and becoming one of the research areas to overcome the drawback of conventional concrete properties over consistency of high strength concrete at heavy reinforcing structure elements. Concrete is a composite material, comprising a matrix of aggregate and a binder, which holds the matrix together. Concrete of various types are available, determined by the formulations of binders and the types of aggregate used to suit the application for the material. These variables determine strength, density, as well as chemical and thermal resistance of the finished concrete product. Compaction of concrete is one of the important site operations that together enable the fresh concrete to reach its potential design strength, density and low permeability. Compaction is the process that expels entrapped air from freshly placed concrete and packs the aggregate particles together so as to increase the density of the concrete. Compaction significantly increases the ultimate strength of concrete and enhances the bond with reinforcement. It also increases the abrasion resistance and durability of the concrete, decreases the permeability and helps to minimize its shrinkage and creep characteristics.

Self-compacting concrete is a highly flowable type of concrete that spreads into the form without the need for mechanical vibration. Self-compacting concrete (SCC) is a non-segregating concrete that is placed by means of its own weight. The importance of self-compacting concrete is, that maintains all concrete's durability and characteristics, meeting expected performance requirements. In certain instances, the addition of superplasticizers and viscosity modifier are added to the mix, reducing bleeding and segregation. Concrete that segregates losses strength and results in honeycombed areas next to the formwork. A well-designed SCC mix does not segregate, has high deformability and excellent stability characteristics[1].

Self-compacting concrete produces resistance to segregation by using mineral fillers or fines and using special admixtures. Selfconsolidating concrete is required to flow and fill special forms under its own weight, it shall be flowable enough to pass through highly reinforced areas, and must be able to avoid aggregate segregation. This type of concrete must meet special project requirements in terms of placement and flow. Self-compacting concrete with a similar water cement or cement binder ratio will usually have a slightly higher strength compared with traditional vibrated concrete, due to the lack of vibration giving an improved interface between the aggregate and hardened paste. The concrete mix of SCC must be placed at a relatively higher velocity than that of regular concrete. Shazim Ali Memon et al [6] conducted a study of substantiate the feasibility of developing low cost SCC using RHA. Test has been carried out on fresh and hardened properties of SCC using RHA as compared to control concrete. The 
compressive strengths developed by the SCC mixes with RHA were comparable to the control concrete. Cost analysis showed that the cost of ingredients of specific SCC mix is $42.47 \%$ less than that of control concrete.

\section{Tests and Properties of Self Compacting Concrete}

SCC having distinct properties over the fresh mixed concrete can be expressed as:

Filling Ability

This property of the concrete is the ability to flow under its own weight without any vibration provided intentionally.

Passing Ability

This property is the ability of the concrete to maintain its homogeneity.

Segregation Resistance

This is the resistance of the concrete not to undergo segregation when it flows during the self-compaction process.

The tests coming under the above-mentioned categories are tabulated below.

Table 1: Different Tests Conducted on Self Compacted Concrete

\begin{tabular}{|c|c|c|}
\hline Filling Ability Tests & Passing Ability Tests & Segregation Resistance Tests \\
\hline Slump flow test & L-Box Test & V- funnel test at T5 minutes \\
\hline T50cm Slump Flow & J- ring test & GTM screen stability Tests \\
\hline Orimet & U- Box Test & - \\
\hline V-funnel Test & Fill - Box Test & - \\
\hline
\end{tabular}

Source: EFNARC, 2005

Rice milling industry generates a lot of rice husk during milling of paddy which comes from the fields. This rice husk is mostly used as a fuel in the boilers for processing of paddy. Rice husk is also used as a fuel for power generation. Rice husk ash (RHA) remains about $25 \%$ by weight of rice husk when burnt in boilers. It is estimated that about 70 million tons of RHA is produced annually worldwide. Rice Husk is pozzolanic materials having physical and chemical properties and this study was limited to assess those properties. This RHA is a great environment threat causing damage to the land and the surrounding area in which it is dumped. The rice husk itself has a very rough surface which is abrasive in nature. These are hence resistant to natural degradation. This would result in improper disposal problems. So, a way to use these by-products to make a new product is the best sustainable idea. Among all industries to reuse this product, cement, and concrete manufacturing industries are the ones who can use rice husk in a better way[2].

\section{MATERIAL AND METHODS}

Self-compacting concrete (SCC) is an innovative concrete that assumes it can hold sufficient workability without any vibration. It is able to flow under its own weight, completely filling formwork and achieving full compaction, even in the presence of congested reinforcement. The hardened concrete is dense, homogeneous and has the same engineering properties and durability as traditional vibrated concrete. With addition of rice husk ash as cement replacement in SCC provides enhanced characteristics[3].

This study was completely rely on experimental work on the properties of the SCC with standard test methods. The properties of the local aggregate's specific gravity, water absorption and gradation for the mix design of required concrete grade was carried out along with the collection of sampled aggregates. The proportion of concrete ingredients ascertained through mix design was revised through calculation and literature reviews. Necessary ingredients (cement, plasticizer) was accumulated along with rice husk ash. Self-compacting concrete of required grade was formed through trails and properties of fresh concrete was ascertained through slump flow test, L-Box test and V-Funnel test. Concrete cubes were casted and curing was carried out. Compressive strength of cubes was found out and analysis of result was carried out. Proper mix for Self-compacting concrete was adopted from trails for replacement of cement with rice husk ash.

\subsection{Data Collection}

Crusher run materials are widely used for the construction activities in Pokhara valley. Seti river-based sources are widely used for the fine and coarse aggregate due to easy availability and accessibility also known as common stockpile of building material at various construction site of the Pokhara Valley, so sample were collected from Kotre source for coarse crusher run materials and Ramghat source for fine aggregates. Shivam (OPC) cement of Nepal Standard was used for the preparation of design mix of M20 grade of concrete. Table 2 briefly illustrates the different source selected. 
Table 2: Selection of Source for Sample Collection of Ingredients Materials

\begin{tabular}{|l|l|l|l|}
\hline S.N. & Material & Type of Ingredients & Location \\
\hline 1 & Cement & Shivam OPC NS Standard & Pokhara \\
\hline 2 & Sand & Fine Aggregate & Seti River Ramghat, Kaski \\
\hline 3 & Coarse Aggregate & Crusher Run materials & Kotre, Kaski \\
\hline 4 & Water & Boring Water & Pokhara, Kaski \\
\hline
\end{tabular}

\section{A. Methods and Laboratory Procedures for Mix Design of Concrete}

The concrete mix was designed to produce the required grade of concrete having the designated workability, characteristic and compressive strength. Mix design were carried out for the concrete grade M20 as per IS 10262:2009 and IS 456:2000. This mix design principles result that concrete compared to traditional vibrated concrete, normally contains lower coarse aggregate content, increased paste content, low water/powder ratio, increased superplasticizer and sometimes a viscosity modifying admixture.

Table 3: Trails Mix Proportion for Assessing Fresh Properties of Concrete per $0.014 \mathrm{~m}^{3}(\mathrm{in} \mathrm{Kg})$

\begin{tabular}{|c|c|c|c|c|c|c|c|}
\hline \multirow[b]{2}{*}{ Trial } & \multirow[b]{2}{*}{$\mathrm{W} / \mathrm{C}$} & \multirow[b]{2}{*}{ Water } & \multirow[b]{2}{*}{ Cement } & \multicolumn{3}{|c|}{ Aggregate } & \multirow[b]{2}{*}{ Superplasticizer } \\
\hline & & & & Fine & $\begin{array}{c}\text { Coarse of } \\
16 \mathrm{~mm}\end{array}$ & $\begin{array}{c}\text { Coarse of } \\
10 \mathrm{~mm}\end{array}$ & \\
\hline \multicolumn{8}{|l|}{ Set A } \\
\hline TRA1 & 0.41 & 2.25 & 5.47 & 13.61 & 13.61 & - & 0.055 \\
\hline TRA2 & 0.43 & 2.35 & 5.47 & 13.61 & 13.61 & - & 0.055 \\
\hline TRA3 & 0.45 & 2.45 & 5.47 & 13.61 & 13.61 & - & 0.055 \\
\hline TRA4 & 0.47 & 2.55 & 5.47 & 13.61 & 13.61 & - & 0.055 \\
\hline TRA5 & 0.48 & 2.65 & 5.47 & 13.61 & 13.61 & - & 0.055 \\
\hline TRA6 & 0.50 & 2.75 & 5.47 & 13.61 & 13.61 & - & 0.055 \\
\hline TRA7 & 0.52 & 2.85 & 5.47 & 13.61 & 13.61 & - & 0.055 \\
\hline \multicolumn{8}{|l|}{ Set B } \\
\hline TRB1 & 0.54 & 2.95 & 5.47 & 16.33 & 8.17 & 2.72 & 0.055 \\
\hline TRB2 & 0.56 & 3.05 & 5.47 & 16.33 & 8.17 & 2.72 & 0.055 \\
\hline TRB3 & 0.58 & 3.15 & 5.47 & 16.33 & 8.17 & 2.72 & 0.055 \\
\hline TRB4 & 0.59 & 3.25 & 5.47 & 16.33 & 8.17 & 2.72 & 0.055 \\
\hline TRB5 & 0.61 & 3.35 & 5.47 & 16.33 & 8.17 & 2.72 & 0.055 \\
\hline \multicolumn{8}{|l|}{ Set $\mathrm{C}$} \\
\hline TRC1 & 0.50 & 3 & 6.01 & 16.33 & 10.88 & - & 0.060 \\
\hline TRC2 & 0.52 & 3.1 & 6.01 & 16.33 & 10.88 & - & 0.060 \\
\hline TRC3 & 0.53 & 3.2 & 6.01 & 16.33 & 10.88 & - & 0.060 \\
\hline TRC4 & 0.55 & 3.3 & 6.01 & 16.33 & 10.88 & - & 0.060 \\
\hline TRC5 & 0.57 & 3.4 & 6.01 & 16.33 & 10.88 & - & 0.060 \\
\hline
\end{tabular}

The trail mix design was based on the evaluation of the water demand and optimization of the flow and stability of the paste, determination of the proportion of sand, coarse agregates and the doses of admixture to give the required robustness, test for the sensitivity for small variations in quantities, addition of an appropriate amount of coarse aggregate, production of the fresh SCC in the laboratory mixer, perform the required tests and the compressive strength of the SCC in the hardened state was calculated recording breaking load of concrete cubes.

\section{B. Filling Ability Test}

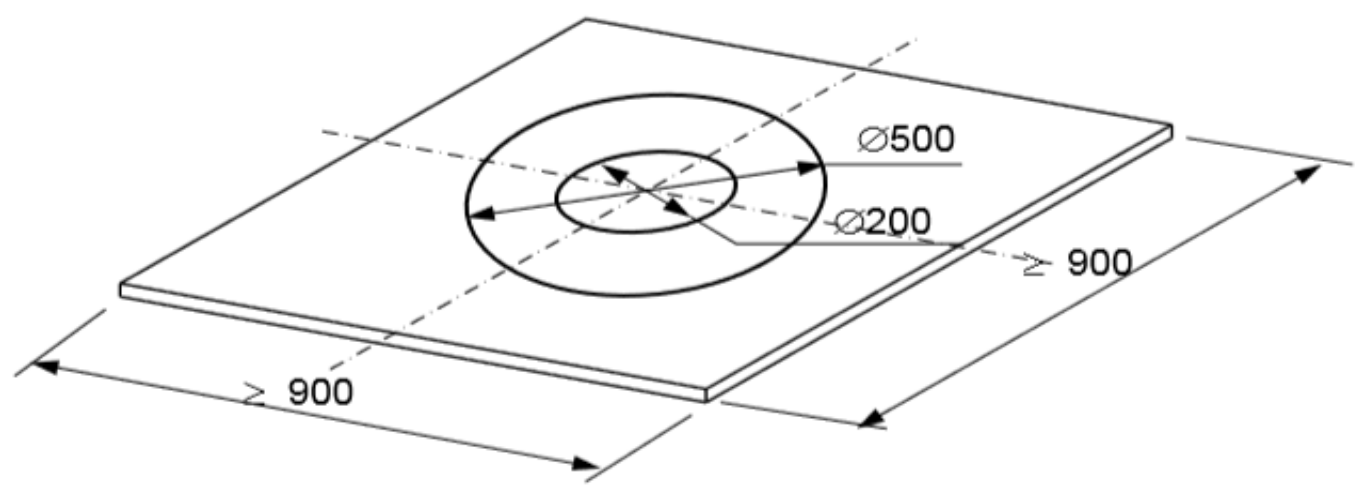

Figure 1: Slump Flow Apparatus (All Dimensions are in mm) 
The cone and baseplate as described in EN 12350-2 was prepared from material and dimensions stated. The cone was placed coincident with the $200 \mathrm{~mm}$ circle on the baseplate and was held in position ensuring that no concrete can leak from under the cone. The cone was filled without any agitation or rodding and surplus was levelled from the top of the cone. The cone filled with concrete was allowed to stand for not more than $30 \mathrm{sec}$; during this time any spilled concrete was removed from the baseplate and the baseplate was ensured damp all over but without any surplus water.[5]

The cone was lifted vertically in one movement without interfering with the flow of concrete. The stop watch was started immediately the cone ceases to be in contact with the baseplate and the time taken was recorded to the nearest $0,1 \mathrm{sec}$ for the concrete to reach the $500 \mathrm{~mm}$ circle at any point. The largest diameter is measured of the flow spread and was record as $\mathrm{dm}$ to the nearest $10 \mathrm{~mm}$. Then, the diameter of the flow spread at right angles was measured to $\mathrm{dm}$ to the nearest $10 \mathrm{~mm}$ and was record as $\mathrm{dr}$ to the nearest $10 \mathrm{~mm}$. The concrete spread was checked for segregation. The cement paste/mortar may segregate from the coarse aggregate to give a ring of paste/mortar extending several millimeters beyond the coarse aggregate.

\section{Passing Ability Test}

The L-box was prepared from material and dimensions stated in the guidelines. The L-box was supported on a level horizontal base and the gate was closed between the vertical and horizontal sections. The concrete was poured from the container into the filling hopper of the L-box and allow to stand for $(60 \pm 10)$ s. Any segregation found was noted and then the gate was raised so that the concrete flows into the horizontal section of the box.[5]

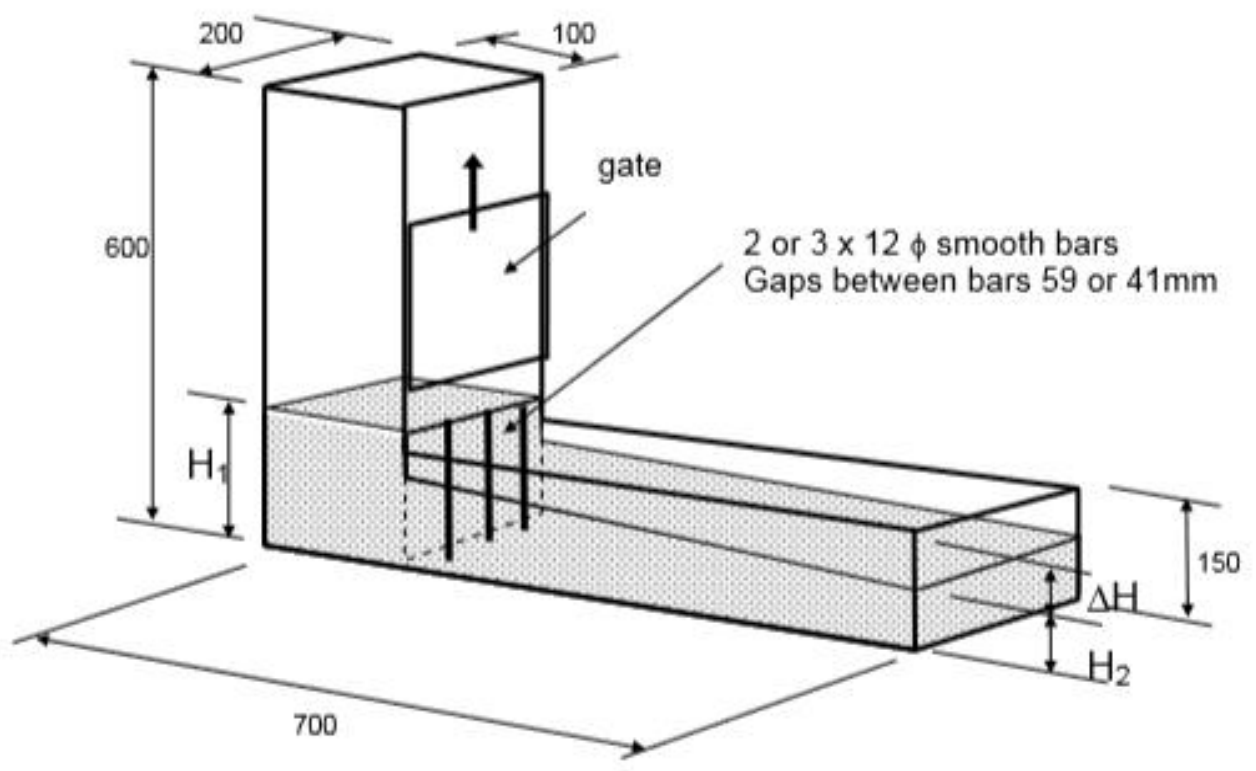

Figure 2: L-Box Apparatus (All Dimensions are in $\mathrm{mm}$ )

When movement was ceased, the vertical distance was measured, at the end of the horizontal section of the L-box, between the top of the concrete and the top of the horizontal section of the box at three positions equally spaced across the width of the box. By difference with the height of the horizontal section of the box, these three measurements were used to calculate the mean depth of concrete as $\mathrm{H} 2 \mathrm{~mm}$. The same procedure was used to calculate the depth of concrete immediately behind the gate as $\mathrm{H} 1 \mathrm{~mm}$.

\section{Segregation Resistance Test}

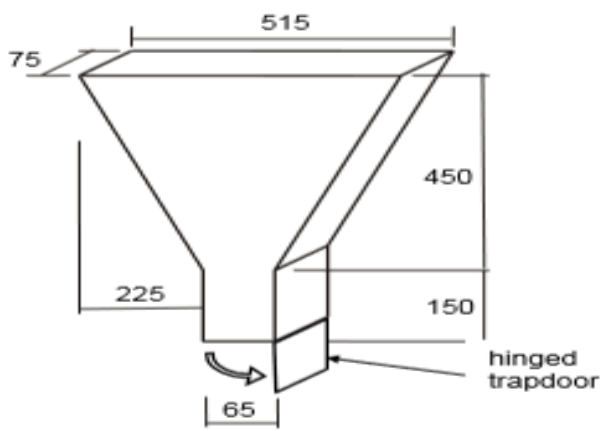

Figure 3: V Funnel Apparatus (All Dimensions are in mm) 
The V-funnel was prepared from material and dimensions stated.in the guidelines. The funnel was cleaned and bottom gate, all the inside surface including the gate was dampened. The gate was closed and the sample of concrete was poured into the funnel, without any agitation or rodding, then strike off the top with the straight edge so that the concrete was flushed with the top of the funnel. The container was placed under the funnel in order to retain the concrete to be passed. After a delay of (10 \pm 2$)$ sec from filling the funnel, the gate was opened and measured the time tv. to $0.1 \mathrm{sec}$, from opening the gate to when it was possible to see vertically through the funnel into the container below for the first time (tv is the V-funnel flow time).[5]

\section{E. Compressive Strength Test}

The compression test was carried out on the cubical shape specimens. The compression test is widely used to determine the compressive strength of hardened concrete at the end of 7 days and 28 days of casting. For which five different sets of samples with $0 \%, 5 \%, 10 \%, 20 \%$ and $30 \%$ replacement of cement with rice husk ash were casted and cured within laboratory conditions. Required quantity of cement, sand, crushed coarse aggregate and water as per design mix of concrete was taken and mixed in dry state. A known quantity of water was applied to dry mix. The moulds were cleaned and oil was applied to the internal surface of the mould. The fresh concrete was filled in the mould continuously without compaction. The top surface of the mould was levelled by removing excess concrete by the use of trowel and date of casting as well as trials was labelled. The moulds were stored for 24 hours at laboratory temperature. Further the cubes were removed from the mould and put into the fresh water with fully submerged. At the end of the 7 days and 28 days of casting three cubes were taken out. The excess water was allowed to drain off make dry and then weight of each cube was taken. The cube was placed at the compression testing machine and load was applied gradually and uniformly till the failure occurs. The maximum crushing load was noted down. Mean compressive strength was calculated for all sets of results.

Compressive strength $(\mathrm{N} / \mathrm{mm} 2)=$ Maximum crushing load / Cross - sectional area of specimen.

\section{F. Rice Husk Ash Production}

Rice husk ash required for the study was collected from the local mills located at Hemaja, Pokhara. Burning process adopted for production of RHA was uncontrolled burning and the obtained RHA was grinned in the Los Angeles Abrasion with specific number of charges and revolutions. In order to achieve the required fines, the drum with $10 \mathrm{~kg}$ of RHA and ten charges of 420 grams each was run for 30 minutes. Then the obtained RHA was sieved in 75 microns sieve for extraction of required sized RHA as only particles less than 75 microns was used in this study.

\section{RESULTS AND DISCUSSION}

Laboratory test result were analysed and compared with the standard code of practice to accept or reject the obtained results. The obtained results of each parameters are discussed with the standard code of practice.

\section{A. Physical Properties of Ingredients Material}

The following physical properties of coarse and fine aggregate were tested in lab and finding of experimental data are listed below. Sieve analysis specified the gradation of aggregate. This process was used to determine whether the aggregates are within the specified range or not.

\section{a) Gradation of Coarse Aggregate}

Gradation, sieve analysis is used to assess the particle size distribution of a granular material by allowing the material to pass through a series of sieves.

The gradation of sampled coarse aggregate is presented in Table 4.

Table 4: Sieve Analysis of Coarse Aggregate

\begin{tabular}{|c|c|c|}
\hline Sieve Size & $\begin{array}{c}\text { Percentage Passing } \\
(\%)\end{array}$ & Specification of DOR \\
\hline $16 \mathrm{~mm}$ & 100 & $90-100 \%$ \\
\hline $12.5 \mathrm{~mm}$ & 82.40 & - \\
\hline $10 \mathrm{~mm}$ & 43.36 & $30-70 \%$ \\
\hline $4.75 \mathrm{~mm}$ & 0.00 & $0-10 \%$ \\
\hline
\end{tabular}

Source: Lab test, 2020

Table 4 indicates gradation are within the specified range, hence aggregates are suitable for the concrete production.

\section{b) Gradation of Fine Aggregate}

Gradation, sieve analysis is used to assess the particle size distribution of a granular material by allowing the material to pass through a series of sieves.

The gradation of sampled fine aggregate is presented in Table 5. 
Table 5: Sieve Analysis of Fine Aggregate Source.

\begin{tabular}{|c|c|c|}
\hline Sieve Size & $\begin{array}{c}\text { Percentage Passing } \\
(\%)\end{array}$ & Specification \\
\hline $10 \mathrm{~mm}$ & 100.00 & $100 \%$ \\
\hline $4.75 \mathrm{~mm}$ & 97.33 & $95-100 \%$ \\
\hline $2.36 \mathrm{~mm}$ & 95.63 & $95-100 \%$ \\
\hline $1.18 \mathrm{~mm}$ & 90.29 & $90-100 \%$ \\
\hline $0.6 \mathrm{~mm}$ & 88.24 & $80-100 \%$ \\
\hline $0.3 \mathrm{~mm}$ & 48.60 & $15-50 \%$ \\
\hline $0.15 \mathrm{~mm}$ & 13.88 & $0-15 \%$ \\
\hline
\end{tabular}

Source: Lab test, 2020

Table 5 reveals that gradation are within the specified range of Zone IV grading limits for fine aggregates (IS: 383-1970).

\section{c) Specific Gravity and Water Absorption}

The result of Specific Gravity are presented in Table 6. Specific gravity was found within the standard range $(>2.5)$ as per Standard Specification for Road and Bridge Works-2073 of DoR, Nepal.

Source: Lab test, 2020

\begin{tabular}{|} 
Table 6: Specific Gravity of Coarse Aggregate \\
\begin{tabular}{|c|c|c|}
\hline Source & Specific Gravity & DOR Specification \\
\hline Kotre Source & 2.69 & $>2.5$ \\
\hline
\end{tabular}
\end{tabular}

The obtained result of water absorption is presented in Table 7. Water absorption of coarse aggregate was comprised within the standard range $(<2 \%)$ as per Standard Specification for Road and Bridge Works- 2073 of DoR, Nepal.

Table 7: Water Absorption of Coarse Aggregate

\begin{tabular}{|c|c|c|}
\hline \multicolumn{2}{|c|}{ Table 7: Water Absorption of Coarse Aggregate } \\
\hline Source & Water Absorption & DOR Specification \\
\hline Kotre Source & $0.35 \%$ & $<2 \%$ \\
\hline
\end{tabular}

Source: Lab test, 2020

\section{B. Flow Properties of Self Compacting Concrete}

The obtained results of various trails and respective flow properties are presented in Table 8 .

Table 8: Various Trails and SCC Flow Test

\begin{tabular}{|c|c|c|c|}
\hline Trials & Slump Flow (mm) & $\begin{array}{c}\text { V-funnel Flow } \\
(\mathrm{sec})\end{array}$ & $\begin{array}{c}\text { L-box Ratio } \\
(\mathrm{h} 2 / \mathrm{h} 1)\end{array}$ \\
\hline TRC3 & 640 & - & - \\
\hline TRC4 & 670 & 12 & 0.71 \\
\hline TRC5 & 710 & 8 & 0.9 \\
\hline Recommended Limits & $600-800 \mathrm{~mm}$ & $8-12 \mathrm{sec}$ & $0.8-1$ \\
\hline
\end{tabular}

Source: Lab Test, 2020.

\section{Compressive Strength of Mix Design of Concrete}

The compressive strength of cube samples was tested as per standards and the obtained results are given below.

The compressive strength of cube samples which were casted as per IS 10262:2009 \& IS 456:2000 (design mix guidelines) were tested as per standards. The reflected results of concrete cubes are given in Table 9.

Table 9: Compressive Strength of Sampled Concrete Cube (in N/mm²)

\begin{tabular}{|c|c|c|c|c|}
\hline & Sample & & IS Code \\
Mix Proportions & 1 & $\begin{array}{c}\text { Days Result } \\
\text { at lab }\end{array}$ & $\begin{array}{c}28 \text { Days Result at } \\
\text { Lab }\end{array}$ & \\
\hline TRA7 & 2 & 18.44 & 28.37 & $>26.6$ \\
\hline TRB5 & 3 & 13.85 & 21.41 & $>26.6$ \\
\hline TRC5 & 18.07 & 27.78 & $>26.6$ \\
\hline
\end{tabular}

Source: Lab test, 2020.

From the results obtained in flow test and compressive strength, trail TRC5 complies with SCC and Strength parameters for study so it was further used in RHA replacement study. 


\section{Flow Properties of SCC with added RHA}

The obtained results of cement replaced with various proportion and respective flow properties are presented in Table 10.

Table 10: Various Trails and SCC Flow Test with RHA Percentage

Source: Lab test, 2020.

Table 10: Various Trails and SCC Flow Test with RHA Percentage
\begin{tabular}{|c|c|c|c|}
\hline RHA ( in \%) & Slump Flow $(\mathrm{mm})$ & V-funnel Flow (sec) & L-box Ratio (h2/h1) \\
\hline 0 & 720 & 9 & 0.92 \\
\hline 5 & 693 & 11.5 & 0.9 \\
\hline 10 & 664 & 15 & 0.7 \\
\hline 15 & 637 & - & 0.65 \\
\hline 20 & 602 & - & - \\
\hline 30 & 595 & - & - \\
\hline Recommended Limits & $600-800 \mathrm{~mm}$ & $8-12 \mathrm{sec}$ & $0.8-1$ \\
\hline
\end{tabular}

\section{E. Compressive Strength of Mix Design of Concrete}

The compressive strength of cube samples which were casted as per IS 10262:2009 \& IS 456:2000 (design mix guidelines) were tested as per standards. The reflected results of concrete cubes are given in Table 11.

Table 11: Compressive Strength of RHA Added Concrete Cube (in N/mm²)

\begin{tabular}{|c|c|c|c|c|c|}
\hline \multirow[b]{2}{*}{ Trail No. } & \multirow[b]{2}{*}{ RHA (in \%) } & \multicolumn{3}{|c|}{ Compressive Strength in $\mathrm{N} / \mathrm{mm}^{2}$ at } & \multirow[b]{2}{*}{ Remarks } \\
\hline & & 7 Day & 28 Day & 45 Day & \\
\hline 1 & 0 & 18.67 & 27.33 & 27.41 & \\
\hline 2 & 5 & 11.19 & 15.19 & 18.52 & \\
\hline 3 & 10 & 8.52 & 12.07 & 14.44 & \\
\hline 4 & 15 & 5.33 & 8.74 & 10.30 & \\
\hline 5 & 20 & 5.85 & 9.85 & 11.63 & \\
\hline 6 & 30 & 4.74 & 8.07 & 9.70 & \\
\hline
\end{tabular}

Source: Lab test, 2020.

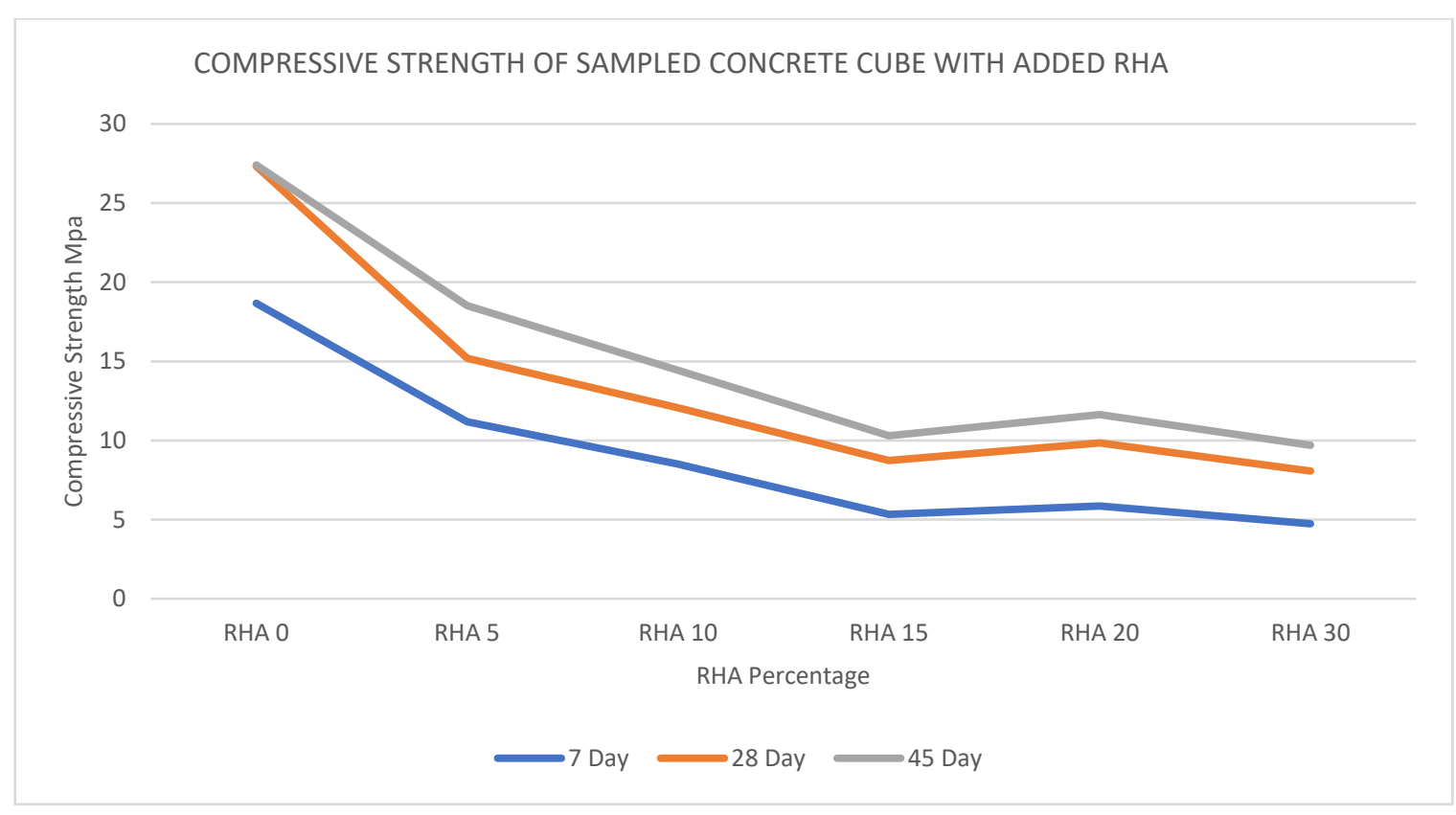

Figure 4: Compressive Strength of Sampled Concrete Cube with Added RHA 
The above figure identifies that the control specimen achieved a compressive strength of $27.33 \mathrm{MPa}$. This result was consistent with the target strength identified in the calculated mix design. The strength development between 7 day and 28 day strength observed in the control is slightly different to the strength development apparent in each of the trial mix designs with RHA as some strength has found to be developed lately which is illustrated through the 45 days strength. However it is evident through review of the above data that inclusion of RHA in replacement of OPC results in decreased strength development. When the cement content is reduced and quantity of pozzolan is increased there is a reduced amount of leftover $\mathrm{Ca}(\mathrm{OH}) 2$ available as a reactive ingredient. As such the remaining amorphous silica is only able to serve as a filler in the mix, and therefore does not successfully contribute to strength development.

\section{CONCLUSION}

The application of SCC has the potential to overcome many limitations currently evident in the construction industry. Through utilization of this material it is possible to construct larger structures with dense reinforcement without affecting its strength characteristics. Hardened concrete testing in the form of compressive strength tests provided necessary data confirming the impact RHA has on the strength parameters of SCC. The test results confirmed that the inclusion of RHA resulted in subsequent reductions. The strength reduction was larger than originally anticipated. As such there was no specific application of RHA considered optimal in this instance. There is however still potential for application of each mix design. In instances requiring lower strength concretes significant replacement of OPC with a cheaper pozzolan creates an economically beneficial product. The final strength properties achieved by RHA did not meet the design compressive strength, the data collated from experimental analysis provides sufficient evidence to support the application of RHA as a SCM. Through attaining further understanding regarding the characteristics of RHA and its interaction with cement there is potential to develop a product suitable for application as a sustainable building material. RHA has been identified as a suitable material for application as a pozzolan.

\section{REFERENCES}

[1] K. Murthy.N, "Mix Design Procedure for Self Compacting Concrete,” IOSR J. Eng., vol. 02, no. 09, pp. 33-41, 2012.

[2] V. Kanthe, S. Deo, and M. Murmu, "Combine use of fly ash and rice husk ash in concrete to improve its properties," Int. J. Eng. Trans. A Basics, vol. 31, no. 7, pp. 1012-1019, 2018.

[3] K. Islam and Z. Hossain, Potential Use of Rice Husk Ash (RHA) in Flowable Fill Concrete, vol. 271, no. 18. 2019.

[4] Department of Roads, "Standard Specifications for Road and Bridge Works 2073," 2001.

[5] The European Project Group, “The European Guidelines for Self-Compacting Concrete Specification, Production and Use," Eur. Guidel. Self Compact. Concr., no. May, p. 63, 2005.

[6] Shazim Ali Memon, Muhammad Ali Shaikh, Hassan Akbar. (2011), "Utilization of Rice Husk Ash as viscosity modifying agent in Self Compacting Concrete" Construction and Building Materials 25 (2011) pp.1044-1048. 